\title{
ADENOSINE DEPRESSES SPONTANEOUS TRANSMITTER RELEASE FROM FROG MOTOR NERVE TERMINALS BY ACTING AT AN $A_{1}$-LIKE RECEPTOR
}

\author{
Susan R. Barry
}

Department of Physical Medicine and Rehabilitation, University Hospital - Room 1D204, University of Michigan, 1500 East Medical Center Drive, Ann Arbor, Michigan 48109-0042, and Marine Biological Laboratory, Woods Hole, MA 02543

(Received in final form March 5, 1990)

\section{Summary}

\begin{abstract}
Adenosine ( $\mathrm{t} \mu \mathrm{M}$ to $1 \mathrm{mM})$ depressed spontaneous transmitter release from frog motor nerve terminals without producing any observable postsynaptic effects. Since this action of adenosine was blocked by $20 \mu \mathrm{M}$ theophylline and $1 \mu \mathrm{M} 8$ phenyltheophylline, adenosine probably acts at a specific receptor on motor nerve terminals to reduce spontaneous transmitter output. The effects of the adenosine analogs, $\mathrm{L}-\mathrm{N}^{6}$-phenylisopropyladenosine (L-PIA, 100pM to $1 \mu \mathrm{M}$ ), D-PIA (100nM to $100 \mu \mathrm{M}$ ), and 5'-N-ethylcarboxamidoadenosine (NECA, $10 \mathrm{nM}$ to $100 \mu \mathrm{M}$ ), were tested on spontaneous transmitter release at the frog neuromuscular junction. LPIA depressed mepp frequency at a threshold concentration of about $1 \mathrm{nM}$, was thirteen times more potent than NECA, and was 294 times more effective than DPIA. The rank-order potency of these analogs indicates that adenosine acts at an $A_{1}$-like receptor to depress spontaneous transmitter release. Inhibitory actions of maximally effective concentrations of adenosine and L-PIA were also blocked by the $A_{1}$-specific antagonist, 1-3-dipropyl-8-cyclopentylxanthine (DPCPX) at a concentration of $100 \mathrm{nM}$. Micromolar concentrations of NECA, an agonist with approximately equal affinity for the $A_{1}$ and $A_{2}$ receptors, produced biphasic effects on mepp frequency. Thus, a second adencsine receptor, perhaps of the $A_{2}$ subtype, may be present on motor nerve terminals and may mediate an increase in spontaneous transmitter release.
\end{abstract}

Adenosine may play an important role in the regulation of transmitter release from vertebrate motoneurons. ATP is stored with acetylcholine (ACh) in cholinergic synaptic vesicles in the Torpedo electric organ (17) and the rat caudate nucleus (33) and may also be stored in synaptic vesicles in vertebrate motoneurons. ATP is released with ACh from motor nerve terminals and may be hydrolyzed to adenosine in the synaptic cleft $(31,37)$. In addition, ATP is released from contracting skeletal muscie (6). Thus, adenosine levels in the synaptic cleft may increase with increasing transmitter output. Silinsky (37) has estimated that the concentration of adenine nucleotides in the synaptic cleft may reach $100 \mu \mathrm{M}$ following brief repetitive stimulation. This concentration is up to 100 -fold greater than the doses necessary to produce physiological effects (38). Thus, adenosine, which is produced during neuronal stimulation, may play a feedback role in neuromuscular transmission.

At the frog and rat neuromuscular junction (NMJ), adenosine decreases both evoked and spontaneous $\mathrm{ACh}$ release $(7,20,32,38)$. Adenosine reduces the quantal content of endplate potentials (epps), which are evoked by nerve stimulation, and reduces the frequency of spontaneous miniature endplate potentials (mepps), which can be recorded in the absence of nerve stimulation. These actions are not accompanied by any observable postsynaptic effects.

The depressant effects of adenosine on transmitter release may be mediated by specific adenosine receptors on motor nerve terminals. Two types of adenosine receptors, $A_{1}$ and $A_{2}$, are 
found on the plasma membrane of several cell types, including adipocytes, platelets, glia, and neurons $(5,10,11,14,19,25,26,43)$. $A_{1}$ and $A_{2}$ receptors can be distinguished pharmacologically using the adenosine analogs, L-PIA, its stereoisomer D-PIA, and NECA.

Ribiero and Sebastiaxo (29) have characterized the receptor involved in the inhibitory action of adenosine on evoked transmitter release at the frog NMJ. The effects of several adenosine analogs were studied on the amplitude of the nerve-evoked muscle twitch. Ribiero and Sebastião reported that the rank-order potency of these analogs did not fit the criteria for an $A_{1}$ or $A_{2}$ adenosine receptor and suggested that a third receptor, an $A_{3}$ receptor, may be present on motor nerve and other nerve terminals (30). They postulated further that adenosine may act at this receptor to block calcium entry through voltage-sensitive calcium channels in the nerve terminal membrane. In contrast, Silinsky has reported that adenosine depresses transmitter release from frog motoneurons by a mechanism which does not involve inhibition of calcium influx $(38,41)$ or changes in the intracellular calcium concentration $(22)$. Other investigators $(7,20)$ have also reported that adenosine does not reduce calcium influx into motor nerve terminals.

I have characterized the adenosine receptor which mediates a decrease in spontaneous transmitter release from frog motoneurons. Spontaneous transmitter release, unlike evoked transmitter output, is not dependent upon the influx of calcium ions through voltage-sensitive calcium channels. Instead, resting spontaneous transmitter release probably varies with the resting levels of calcium within the nerve terminal (1). The evidence presented below indicates that adenosine acts at an $A_{1}$-like receptor to reduce spontaneous transmitter release from frog motor nerve terminals. Preliminary reports of some of this work have been published $(2,3)$.

\section{Methods}

The cutaneous-pectoris nerve-muscle preparation was isolated from small frogs (Rana pipiens, 1.5 to 2.5 inches, Kons Scientific, Germantown, Wisconsin). The nerve-muscle preparation was pinned out in a recording dish lined with Sylgard resin and continually perfused with frog Ringer (115mM NaCl, $1.8 \mathrm{mM} \mathrm{CaCl} 2,2 \mathrm{mM} \mathrm{KCl}, 5 \mathrm{mM}$ glucose, $5 \mathrm{mM}$ Tris $\mathrm{HCl}, \mathrm{pH} 7.2$ ). Intracellular recordings of mepps were made with $20-40 \mathrm{Mn}$ glass microelectrodes placed in the endplate region of the muscle fiber. Microelectrodes were usually filled with $3 \mathrm{M} \mathrm{KCl}$. In most cases, muscle resting potentials of about $-95 \mathrm{mV}$ could be obtained for several hours. During the winter, however, the resting potential of the muscle fibers depolarized over time. The problem was corrected by filling the microelectrodes with a $250 \mathrm{mM} \mathrm{KCl}$ solution as opposed to a $3 \mathrm{M} \mathrm{KCl}$ solution. This change in the filling solution reduced the muscle resting potential by about $10 \mathrm{mV}$ but had no other effects on the experimental results. Recordings were made at $18-21^{\circ} \mathrm{C}$. Bath temperature was controlled by a peltier device. In any one experiment, the temperature did not vary by more than $1^{\circ} \mathrm{C}$. Drugs were applied by perfusion.

Mepps result from the spontaneous release of single quanta of $\mathrm{ACh}$, of ten from the unstimulated motor nerve terminal. At the frog NMJ, mepps usually occur at a rate of 0.1 to 10 per second. A change in mepp frequency which was not accompanied by a change in mepp size was interpreted as a change in spontaneous transmitter release (23).

Data are presented from sixty-six experimental preparations in which mepp frequency remained stable for several hours. The mean values for mepp frequency recorded at a given endplate in normal Ringer varied by no more than $15 \%$ between the beginning and end of an experiment. To determine the baseline mepp frequency generally 10 minutes of continuous recordings were obtained. The continuous recording was divided into consecutive recording periods or bins of ten seconds duration, and the values for mepp frequency calculated for each recording bin were compared. If the mepp frequencies in each bin differed from each other by more than two-fold, then mepp frequency was considered too variable for further experimentation, and another endplate was sampled. Similarly, if mepps occurred in high frequency bursts, the endplate was rejected for further study. The baseline mepp frequency obtained in Figure 1 is an example of the most variable baseline mepp frequency used in these experiments.

The effects on mepp frequency of adenosine agonists and antagonists were measured ten to twenty minutes after the drug had been introduced to the preparation, and the change in mepp 
frequency had plateaued. Values for mean mepp frequencies in the presence of the drug were calculated by averaging the values for mepp frequency of a minimum of thirty consecutive tensecond recording bins. Following drug application, the preparation was washed in normal Ringer for a minimum of thirty minutes. If mepp frequency returned to a value within $15 \%$ of the baseline mepp frequency, then the effect of the agent was considered completely reversible. A second concentration of the drug or a different compound was then applied to the preparation. In five experiments, increasing concentrations of the same adenosine agonist were serially applied to the same endplate. At the end of the experiments, the preparations were washed with normal Ringer in order to ensure that baseline mepp frequency had returned to the pretreatment value.

Mean mepp frequencies obtained from one endplate in the presence of the drug were compared to the pretreatment mepp frequency using the two-sample Student's $t-t e s t$. In general, a change in mean mepp frequency of at least $20 \%$ was necessary to produce a statistically significant $(p<0.05)$ change in mepp rate.

The amplitudes of mepps were measured directly from the oscilloscope. Mepp amplitudes were divided into $0.2 \mathrm{mV}$ size bins, and the bins were plotted against the frequency of their occurrence. Mepp size histograms obtained from one endplate in different recording solutions were compared statistically using the Kolmogorov-Smirnov test $(p<0.05)$.

Adenosine and its analogs, L-PIA, D-PIA, and NECA, were dissolved directly into frog Ringer. Theophylline and 8-phenyltheophylline, at concentrations of 1 to $10 \mathrm{mM}$, were dissolved in $0.1 \mathrm{~N} \mathrm{NaOH}$ and diluted with Ringer to a final concentration of 1 to $20 \mu \mathrm{M}$. The $A_{1}$ specific antagonist, 1,3-dipropyl-8-cyclopentylxanthine (DPCPX), was dissolved at a concentration of $100 \mu \mathrm{M}$ in $0.2 \mathrm{~N} \mathrm{NaOH}$ before dilution with Ringer to its final concentration. Adenosine and theophylline were obtained from Sigma Chemical Co. (St. Louis, MO); L-PIA, D-PIA, NECA, and DPCPX were purchased from Research Biochemicals, Inc. (Natick, MA).

\section{$\underline{\text { Results }}$}

Adenosine, in a concentration-dependent manner, reversibly reduced mepp frequency without affecting the muscle resting potential or mepp size $(n=14$, Fig. 1). Thus, adenosine depressed spontaneous transmitter release from frog motor nerve terminals in the absence of any observable postsynaptic actions.


FIG 1:

Adenosine $(10 \mu \mathrm{M})$ reversibly depressed mepp frequency but had no effect on mepp size. In (A), mepp frequencies for one minute recording periods were plotted against time. Adenosine reduced mepp frequency by $60 \%$ (p<0.001). In (B), the amplitudes of mepps were grouped into $0.2 \mathrm{mV}$ size bins, and the bins were plotted against the frequency of their occurrence. Amplitude histograms were plotted after measuring 100 mepps in Ringer and 100 mepps in $10 \mu \mathrm{M}$ adenosine. Adenosine did not affect the amplitude distribution of the mepps ( $>0.2)$. ADO = adenosine. 
In one experiment, $50 \mu \mathrm{M}$ adenosine did not depress but enhanced mepp frequency by $43 \%$ $(p<0.05)$. This effect was reversible. In a second experiment, $1 \mathrm{mM}$ adenosine produced a transient increase followed by a sustained decrease in mepp frequency. Stimulatory effects of adenosine on neuromuscular transmission have also been reported by Silinsky (36).

The inhibitory effect of adenosine on mepp frequency was mediated by an adenosine receptor. In three out of three experiments, the decrease in mepp frequency produced by $10 \mu \mathrm{M}$ adenosine was completely blocked by $20 \mu \mathrm{M}$ theophylline, an adenosine receptor antagonist $(15,35)$. At $20 \mu \mathrm{M}$, theophylline may produce a small increase in resting mepp frequency, but this effect was not statistically significant (4). Similarly, the adenosine antagonist, 8-phenyltheophylline, at $1 \mu \mathrm{M}$, reversed the inhibitory action of $2.5 \mu \mathrm{M}$ adenosine ( $\mathrm{n}=2$ preparations).

Theophylline and 8-phenyltheophylline block both the $A_{1}$ and $A_{2}$ adenosine receptors with approximately equal affinity (14). In contrast, 1,3-dipropyl-8-cyclopentylxanthine (DPCPX) is a selective antagonist for the $A_{1}$ receptor. At a concentration of $100 \mathrm{nM}$, DPCPX completely reversed the effects of $10 \mu \mathrm{M}$ adenosine in one preparation and partially blocked adenosine's action in a second experiment. In four preparations, 100nM DPCPX reversed completely the inhibitory effects of $1 \mu \mathrm{M}$ L-PIA, a potent $A_{1}$ agonist, and partially inhibited L-PIA's action in a fifth (Fig. 2). The direct effects of $100 \mathrm{nM}$ bPCPX on mepp frequency were variable. DPCPX enhanced mean mepp frequency by $99 \%(p<0.05)$ in one of the seven experiments. In the other preparations, DPCPX produced both small increases and decreases in mepp frequency but these changes were not statistically significant.

In one experiment, $10 \mu \mathrm{M}$ adenosine depressed mepp frequency by $23 \% \quad(p<0.05)$ in the absence of DPCPX but enhanced mepp frequency by $105 \%(p<0.001)$ in the presence of $100 \mathrm{nM}$ DPCPX. DPCPX, in the absence of adenosine, also increased mepp frequency but only by $49 \%$ $(p<0.05)$. Thus, DPCPX may have blocked an inhibitory effect and unmasked an excitatory action of adenosine.



FIG. 2:

100nM DPCPX partially blocked the inhibitory effects of $1 \mu \mathrm{M} \mathrm{L-PIA}$ on spontaneous transmitter release. Data represent the mean values for mepp frequencies recorded from a single endplate. $1 \mu \mathrm{M}$ L-PIA significantly depressed mepp frequency by $61 \%$ while $1 \mu \mathrm{M}$ L-PIA in combination with $100 \mathrm{nM}$ DPCPX significantly reduced mepp frequency by only $34 \%$. The difference between the values for mepp frequency in the presence of $1 \mu \mathrm{M}$ L-PIA and in the presence of $1 \mu \mathrm{M}$ L-PIA and 100nM DPCPX was statistically significant. $100 \mathrm{nM}$ DPCPX reduced mepp frequency by $23 \%$ but this effect was not significant. Please note that the action of $1 \mu \mathrm{M}$ L-PIA was only partially reversible after thirty minutes of washing with Ringer. 
The adenosine analogs, L-PIA, D-PIA, and NECA, all reduced mepp frequency without affecting the muscle's resting potential or mepp size. To construct a concentration-response curve (Fig. 3), the data from forty-six experiments were pooled. The data from four to seven different endplates were used to construct each point of the concentration-response curve.

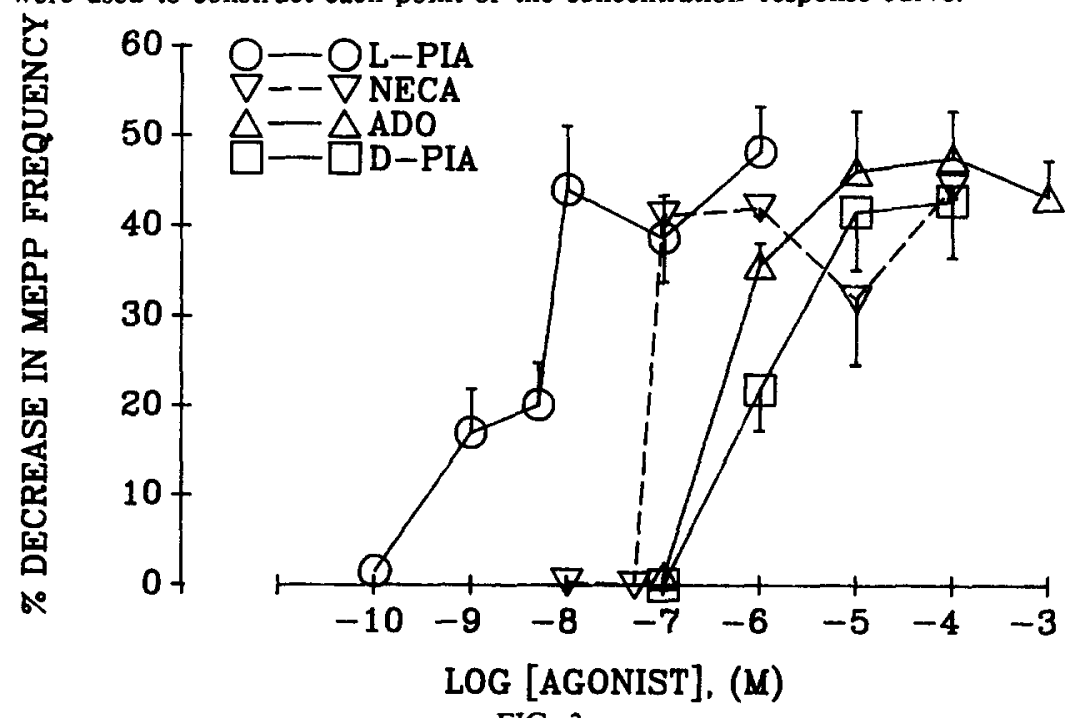

FIG. 3:

Concentration-response curves for the depressant effect of L-PIA, NECA, adenosine, and D-PIA on mepp frequency. Each point represents the mean \pm SEM of changes in mepp frequency recorded from four to seven endplates. In these experiments, the only action of adenosine, L-PIA, and D-PIA was to reduce mepp frequency. In contrast, NECA, at concentrations at or above $1 \mu \mathrm{M}$, produced transient (one minute) increases in mepp frequency which were preceded or followed by more prolonged reductions in mepp rate. The percent depression in mepp frequency due to NECA was calculated for the periods during which mepp frequency was depressed. $A D O=$ adenosine.

L-PIA was the most potent adenosine analog in depressing mepp frequency. At a concentration as low as $1 \mathrm{nM}$, L-PIA depressed mepp frequency by a mean of $17 \%$ while at $10 \mathrm{nM}$, L-PIA produced a maximal reduction in mepp rate. The greatest reduction in mepp frequency produced by adenosine and its analogs was about $50 \%$. The concentrations which produced halfmaximal effects were measured from the concentration-response curves (Fig. 3) to be $5.1 \mathrm{nM}$ for L-PIA, 68nM for NECA, 460nM for adenosine, and 1500nM for D-PIA. Thus, L-PIA was 13 times more potent than NECA and 294 times more potent than D-PIA in reducing spontaneous $A C h$ release. The rank order potency of adenosine analogs in depressing mepp frequency was $L-$ PIA $>$ NECA $>$ adenosine $>$ D-PIA.

The effects of L-PIA and D-PIA on mepp frequency differed from the actions of NECA in at least three ways. Effects of NECA $(100 \mathrm{nM}$ to $100 \mu \mathrm{M})$ were completely reversible. In contrast, the effects of L-PIA and D-PIA completely reversed at concentrations below $1 \mu \mathrm{M}$ but only partially reversed, after thirty minutes, at concentrations of $1 \mu \mathrm{M}, 10 \mu \mathrm{M}$, and $100 \mu \mathrm{M}$.

The actions of L-PIA and D-PIA on mepp frequency were concentration-dependent at all concentrations tested. NECA depressed mepp frequency in a concentration-dependent manner at concentrations at or below $1 \mu \mathrm{M}$. However, the depressant effect of NECA at $10 \mu \mathrm{M}$ were less than that seen at lower concentrations, probably because, at submicromolar concentrations, NECA produced only an inhibitory effect on mepp frequency while, at micromolar concentrations, NECA both inhibited and stimulated spontaneous transmitter release. In four out of four trials, application of $1 \mu \mathrm{M}$ NECA produced an initial enhancement followed by a sustained reduction in mepp frequency (Fig. 4a). With $10 \mu \mathrm{M}$ NECA, decreases in mepp rate were preceded or followed by oscillatory changes in frequency in two out of five experiments (Fig. 4b). At $100 \mu \mathrm{M}$, the only effect of NECA was to reduce mepp frequency in three experiments but, in one preparation, the 
depression in mepp frequency was preceded by an enhanced rate of mepps. Oscillations in mepp frequency produced by micromolar concentrations of NECA were two to three times greater than the variations in mepp frequency observed in normal Ringer. Thus, NECA, at concentrations at or above $1 \mu \mathrm{M}$, produced biphasic effects on spontaneous transmitter release.



FIG. 4:

Bimodal effects of NECA on mepp frequency. NECA, at concentrations of $1 \mu \mathrm{M}$ (A) and $10 \mu \mathrm{M}$ (B) both enhanced and depressed mepp frequency. Mepp frequencies for fifty-second $(A)$ or thirty second $(B)$ recording periods were plotted against time.

Even in those preparations in which NECA produced only a depressant effect on mepp frequency, the inhibitory effects of 10 and $100 \mu \mathrm{M}$ NECA developed more slowly than the actions of adenosine, L-PIA, D-PIA, or 100nM NECA. The time period from the introduction of the drug to a steady-state change in mepp frequency was estimated from the plots of mepp frequency against time. The effects of adenosine, L-PIA, D-PIA and 100nM NECA reached a steady-state within two to four minutes. Values varied from $2.0 \pm 1.0$ minutes (mean \pm SEM) for $1 \mu \mathrm{M}$ D-PIA to $4.3 \pm 1.9$ minutes for $5 \mathrm{nM}$ L-PIA. In contrast, the inhibitory actions of $10 \mu \mathrm{M}$ and $100 \mu \mathrm{M}$ NECA did not develop for an average of $17 \pm 3.6$ minutes and $7.0 \pm 1.5$ minutes respectively. This delay in NECA's inhibitory action may indicate that NECA is producing more than one effect on spontaneous transmitter release.

\section{Discussion}

The relative effectiveness of L-PIA, D-PIA, and NECA in reducing mepp frequency indicates that adenosine acts at an $A_{1}$-like receptor to depress spontaneous transmitter output from frog motoneurons. L-PIA decreased mepp frequency at a threshold concentration of about InM and produced maximal effects at a concentration of $10 \mathrm{nM}$. L-PIA acts at nanomolar concentrations at $A_{1}$ but not $A_{2}$ receptors $(14,19,25,43,44)$. The difference in potency of the stereoisomers, L-PIA and D-PIA, in reducing spontaneous release was about 300 -fold. High stereoselectivity for L-PIA over D-PIA is a characteristic of $A_{1}$ but not $A_{2}$ receptors $(8,12,14,42)$. Finally, L-PIA was about thirteen times more potent than NECA at depressing spontaneous transmitter release. At $A_{1}$ receptors, L-PIA is more active than NECA while the reverse is true at $A_{2}$ receptors $(14,19,25)$. 
The effects of DPCPX at the frog neuromuscular junction also support the hypothesis that adenosine reduces spontaneous release at an $A_{1}$-like adenosine receptor on frog motoneurons. Inhibitory actions of maximally-effective concentrations of adenosine and L-PIA were blocked by $100 \mathrm{nM}$ DPCPX. In rat whole brain membranes, DPCPX binds with 700 times greater affinity to the $A_{1}$ as opposed to the $A_{2}$ receptor (9). In these membranes, at a concentration of $100 \mathrm{nM}$, DPCPX binds almost exclusively to the $A_{1}$ receptor (24).

In other nerve cells, the $A_{1}$ adenosine receptor is coupled to $G_{j}$, a pertussis toxin-sensitive guanine nucleotide-binding protein (16). Pertussis toxin blocks the inhibitory effects of adenosine on spontaneous and evoked transmitter release in rat and frog motor nerve terminals (41). These data support the hypothesis that adenosine depresses $\mathrm{ACh}$ output from motor nerve terminals by activation of an $A_{1}$ receptor.

The rank-order potency of adenosine analogs in depressing mepp frequency is different than the rank-order potency of these analogs in reducing the nerve-evoked twitch of the frog sartorius muscle as reported by Ribiero and Sebastião (29). The half-maximal concentrations for effects of L-PIA and NECA on the nerve-evoked twitch were higher than those reported here for effects on mepp frequency. These investigators also found that L-PIA and NECA were almost equipotent in depressing twitch tension, and that L-PIA was only ten times more effective than D-PIA. Since the rank-order potency for these analogs in depressing evoked release did not match the rank-order potency for the $A_{1}$ or $A_{2}$ subtype, Ribeiro and Sebastião suggested that a third receptor, the $A_{3}$ receptor, may mediate inhibition of evoked $A C h$ release.

The differences between my data and those of Ribeiro and Sebastião may result from differences in the species of frogs, the nerve-muscle preparations, or the compositions of the Ringer that were used. Alternatively, the differences may result from the different methods used to measure neuromuscular transmission. I measured spontaneous transmitter release by observing the frequency of mepps at single endplates, while Ribeiro and Sebastião measured evoked transmitter release by measuring the size of the nerve-evoked twitch produced, not at a single endplate, but in the whole muscle. This difference may explain why L-PIA, NECA, and adenosine were less potent in reducing the nerve-evoked twitch than in depressing mepp frequency. The neuromuscular junction possesses a higher safety factor of transmission (21). Following an action potential in the motoneuron, more $\mathrm{ACh}$ is released than is necessary to produce an action potential or twitch in the muscle fiber. Before an effect on twitch tension will be observed, adenosine or its analogs must depress evoked transmitter release to a level below the safety factor. Thus, the concentration of adenosine necessary to reduce twitch tension in the whole muscle may be greater than that necessary to reduce spontaneous release at a single endplate.

It is also possible that adenosine, its agonists, and antagonists exert direct effects on twitch tension development. We have found that the adenosine receptor antagonist, aminophylline, significantly enhances twitch tension in the directly-stimulated frog semitendinosus muscle at a concentration as low as $25 \mu \mathrm{M}$ (34). This direct effect of aminophylline on muscle force generation may result from adenosine receptor blockade (28).

Adenosine may inhibit evoked and spontaneous $A C h$ release by different receptors or different mechanisms (30). However, Ribeiro and his co-workers have found that the $A_{1}$ specific antagonist, DPCPX, blocks adenosine-induced inhibition of evoked ACh release from the rat phrenic nerve (13) while I have found that DPCPX reverses adenosine-induced depression of spontaneous release. The results of these experiments suggest that inhibition of evoked and spontaneous release may be mediated by the same receptor. My results also indicate that adenosine inhibits spontaneous $A C h$ release at an $A_{1}$ receptor and stimulates spontaneous $A C h$ release perhaps at a second receptor of the $A_{2}$ subtype (see below). The $A_{3}$ receptor described by Ribeiro and Sebastiáo $(29,30)$ may actually represent a combination of the $A_{1}$ and $A_{2}$ receptors (39).

At $A_{1}$ receptors in platelet, fat, and brain cells, adenosine depresses adenylate cyclase activity $(19,25,43,44)$. Adenosine may decrease mepp frequency by acting at an $A_{1}$ receptor to reduce adenylate cyclase activity and, thus, cyclic AMP levels in motor nerve terminals. However, an increase in cyclic AMP levels in motoneurons has been reported both to enhance $(18,27,45)$ and 
depress (38) transmitter release. Further studies are necessary to determine whether adenosine acts at an $A_{1}$ receptor on motor nerve terminals to depress adenylate cyclase activity, and whether consequent changes in neuronal cyclic AMP levels affect spontaneous transmitter release.

Finally, NECA, an agonist with approximately equal affinity for the $A_{1}$ and $A_{2}$ receptor, produced biphasic effects on spontaneous transmitter release. Silinsky and his co-workers $(36,40)$ have also reported biphasic or stimulatory effects on mepp frequency of adenosine and its analogs. These data indicate that adenosine may exert a second, excitatory action on spontaneous transmitter output.

Results from other experiments also suggest that adenosine stimulates $A C h$ release from motonerurons. In one out of three experiments, adenosine, in combination with the $A_{1}$-specific antagonist, DPCPX, stimulated spontaneous transmitter output. Ribeiro and his co-workers (13) have also reported excitatory effects of NECA on evoked release at the rat NMJ when NECA was applied in the presence of DPCPX. Thus, DPCPX may block adenosine's inhibitory action on $\mathrm{ACh}$ release and unmask an excitatory effect of adenosine. Blockade of adenosine's inhibitory actions with pertussis toxin also reveals excitatory effects of adenosine (40). Finally, studies using adenosine antagonists suggest that adenosine stimulates spontaneous release. For example, in hyperosmotic Ringer, theophylline $(10 \mu \mathrm{M})$ and adenosine deaminase $(0.1$ to 0.5 units $/ \mathrm{ml})$ depressed mepp frequency by blocking an excitatory action of endogenously-present adenosine (4).

NECA both inhibited and stimulated mepp frequency in the micromolar concentration range which is the range in which NECA is active at the $A_{2}$ receptor in other cell types $(14,25)$. Bimodal effects of adenosine and NECA on adenylate cyclase activity have been observed on platelet (26), cultured glial (44), and retinal cells (5). Biphasic effects probably result from the existence of both $A_{1}$ and $A_{2}$ receptors on these cells. Thus two adenosine receptors may be present on frog motor nerve terminals. At an $A_{1}$ receptor, adenosine may inhibit while, at a second receptor, perhaps of the $A_{2}$ subtype, adenosine may stimulate spontaneous transmitter release.

\section{Acknowledgements}

Supported by NSF Grant BNS 8506778 and a Kuffler fellowship from the Marine Biological Laboratory.

\section{References}

1. E. ALNAES and R. RAHAMiMOFF, J. Physiol. 248 285-306 (1975).

2. S.R. BARRY, Biol. Bull. 171491 (1986).

3. S.R. BARRY, Biol. Bull. 173 (1987).

4. S.R. BARRY, J. Neurosci. $\underline{8}$ 4427-4433 (1988).

5. C. BLAZYNSKI, J. Neurosci. 7 2522-2528 (1987).

6. I.A. BOYD and T. FORRESTER, J. Physiol. 199 115-135 (1968).

7. D.D. BRANISTEANU, I.D. HAULICA, B. PROCA, and B.G. NHUE, NaunynSchmiedeberg's Arch. Pharmacol. 308 273-279 (1979).

8. R.F. BRUNS, J.W. DALY, and S.H. SNYDER, Proc. Natl. Acad. Sci. 77 5547-5551 (1980).

9. R.F. BRUNS, J.H. FERGUS, E.W. BADGER, J.A. BRISTOL, L.A. SANTAY, J.D. HARTMAN, S.J. HAYS, and C.C. HUANG, Naunyn-Schmiedeberg's Arch. Pharmacol. $\underline{335}$ 59-63 (1987).

10. G. BURNSTOCK, Cell Membrane Receptors for Drugs and Hormones: A Multidisciplinary Approach. R.W. Straub and L. Bolis (eds), 107-118, Raven Press, New York (1978).

11. G. BURNSTOCK and N.J. BUCKELEY, Methods Used in Adenosine Research (Methods in Pharmacology Series). D.M. Paton (ed), 193-212, Plenum Press, New York (1985).

12. M.G. COLLIS, Br. J. Pharmac. 78 207-212 (1983).

13. P. CORREIA-DE-SA, J.L. FOUGO, A.M. SEBASTIAO, and J.A. RIBEIRO, Adenosine Receptors in the Nervous System. J.A. Ribeiro (ed), 196, Taylor \& Francis (1989).

14. J.W. DALY, J. Med. Chem. 25 197-207 (1982).

15. J.W. DALY, R.F. BRUNS, and S.H. SNYDER, Life Sci. 28 2083-2097 (1981).

16. A.C. DOLPHIN and S.A. PRESTWICH, Nature 316 148-150 (1985). 
17. M.D. DOWDALL, A.F. BOYNE, and V.P. WHITTAKER, J. Biochem. 140 1-12 (1974).

18. K.L. DRETCHEN, F.G. STANDAERT, L.R. SKIRBOLL, and V.H. MORGENROTH III, Nature 264 79-81 (1976).

19. C. EBERSOLT, J. PREMONT, A. PROChIANTZ, M. PEREZ, and J. BOCKAERT, Brain Res. 256 123-129 (1983).

20. B.L. GINSBORG and G.D.S. HIRST, J Physiol., 224 629-645 (1972).

21. A.D. GRINNEL and A.A. HERRERA, J. Physiol. 307 301-317 (1980).

22. J.M. HUNT and E.M. SILINSKY, Neurosci. Abs. 15484 (1989).

23. B. KATZ, The Release of Neurotransmitter Substances, 11-12, Charles C. Thomas, Springfield, Illinois (1969).

24. K.S. LEE and M. REDDINGTON, Brain Res. 368 394-398 (1986).

25. C. LONDOS, D.M.F. COOPER, and J. WOLFF, Proc. Natl. Acad. Sci. 77 2551-2554 (1980).

26. C. LONDOS, and J. WOLFF, Proc. Natl. Acad. Sci. 74 5482-5486 (1977).

27. M.D. MIYAMOTO, B.McL. BRECKENRIDGE, J. Gen. Physiol. 63 609-624 (1974).

28. D.M. MURCIANO, N. AUBIER, H. VIRES and R. PARIENIE, J. Appl. Physiol. $\underline{63}$ 51-57 (1987).

29. J.A. RIBEIRO and A.M. SEBASTIAO, Br. J. Pharmac. 84 911-918 (1985).

30. J.A. RIBEIRO and A.M. SEBASTIAO, Prog. in Neurobiol. 26 179-209 (1986).

31. J.A. RIBEIRO and A.M. SEBASTIAO, J. Physiol. 384 571-585 (1987).

32. J.A. RIBEIRO and J. WALKER, Br. J. Pharmac. 54 213-218 (1975).

33. P.J. RICHARDSON and S.J. BROWN, J. Neurochem. 48 662-630 (1987).

34. J.W. RIDINGS, S.R. BARRY, and J.A. FAULKNER, J. Appl. Physiol. 67 671-676 (1989).

35. A. SATTIN and T.W. RALL, Molec. Pharmacol. 6 13-23 (1970).

36. E.M. SILINSKY, Br. J. Pharmac. 71 191-194 (1980).

37. E.M. SILINSKY, J. Physiol. 247 145-162 (1975).

38. E.M. SILINSKY, J. Physiol. 346 243-256 (1984).

39. E.M. SILINSK Y, Sem. in Neurosci. 1 (1989).

40. E.M. SILINSKY, C. SOLSONA, and J.K. HIRSH, Br. J. Pharmac. 97 16-18 (1989).

41. E.M. SILINSKY, C.S. SOLSONA, J.K. HIRSH, and J.M. HUNT, Adenosine Receptors in the Nervous System. J.A. Ribeiro (ed), 141-149, Taylor \& Francis (1989).

42. F.W. SMELLIE, J.W. DALY, T.V. DUNWIDDIE, and B.J. HOFFER, Life Sci. 25 1739-1748 (1979).

43. D. VAN CALKER, M. MÜLLER, and B. HAMPRECHT, Nature 276 839-841 (1978).

44. D. VANCALKER, M. MÜLLER, and B. HAMPRECHT, J. Neurochem. $\underline{33}$ 999-1005 (1979).

45. D.F. WILSON, J. Pharm. Exp. Ther. 188 447-452 (1974). 